\title{
ERRATUM
}

Amy C. Rowat · Jesper Brask · Tobias Sparrman

Knud J. Jensen · Göran Lindblom · John H. Ipsen

\section{Farnesylated peptides in model membranes: a biophysical investigation}

Published online: 29 July 2004

(C) EBSA 2004

\section{Eur Biophys J (2003) 33:300-309}

Fig. 1A-D was incorrect and is reproduced correctly here.

The online version of the original article can be found at http:// dx.doi.org/10.1007/s00249-003-0368-x

A. C. Rowat · J. H. Ipsen $(\bowtie)$

MEMPHYS Centre for Biomembrane Physics,

Department of Physics \& Chemistry,

University of Southern Denmark, Campusvej 55,

5230 Odense, Denmark

E-mail: ipsen@memphys.sdu.dk

Tel.: + 45-6-5502560

Fax: + 45-6-6158760

J. Brask

Department of Chemistry, Technical University of Denmark,

2800 Lyngby, Denmark

T. Sparrman

Department of Medical Biochemistry and Biophysics,

Umeå University, 90187 Umea, Sweden

K. J. Jensen

Biophysical Chemistry, Department of Chemistry,

Umeå University, 90187 Umea, Sweden

G. Lindblom

Department of Chemistry, Royal Veterinary and Agricultural

University, 1870 C Frederiksberg, Denmark 
563

Fig. 1A-D Structures of the synthesized farnesylated peptides. (A) Ac-Asn-Lys-AsnCys-(farnesyl)-OMe; (B) Ac-Asn-Lys-Asn-Cys(farnesyl)- $\mathrm{NH}_{2}$; (C) Ac-Cys(farnesyl)-OMe; (D) farnesol
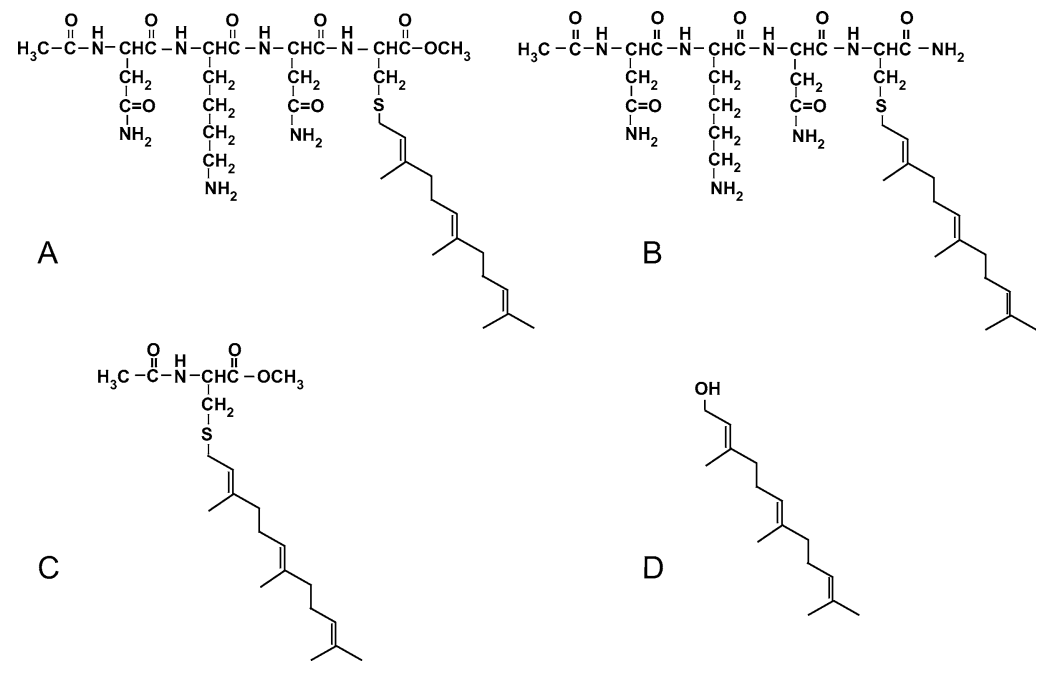

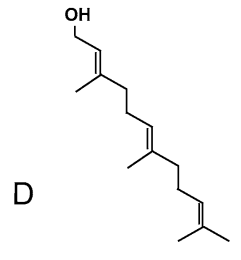

